\title{
Effect of $\operatorname{SiN}_{x}$ diffusion barrier thickness on the structural properties and photocatalytic activity of $\mathrm{TiO}_{2}$ films obtained by sol-gel dip coating and reactive magnetron sputtering
}

\author{
Mohamed Nawfal Ghazzal ${ }^{*} 1$, Eric Aubry ${ }^{2}$, Nouari Chaoui ${ }^{3}$ and Didier Robert ${ }^{4}$
}

\author{
Full Research Paper \\ Address: \\ ${ }^{1}$ Laboratoire de physique des surfaces et interfaces, Université de \\ Mons - UMONS, 20 Place du Parc, 7000 Mons, Belgium, ${ }^{2}$ Institut \\ Femto-ST (UMR 6174 CNRS), UFC, ENSMM, UTBM, 32 Avenue de \\ l'Observatoire, 25044 Besançon Cedex, France, ${ }^{3}$ LCP-A2MC, Institut \\ Jean Barriol, Université de Lorraine, 1 Bd Arago, 57070 Metz, France, \\ and ${ }^{4}$ Laboratoire des Matériaux, Surfaces et Procédés pour la \\ Catalyse, CNRS-UMR 7515, Antenne de Saint-Avold, Université de \\ Lorraine, Rue Victor Demange, 57500 Saint-Avold, France \\ Email: \\ Mohamed Nawfal Ghazzal* - g_nawfel@yahoo.fr \\ * Corresponding author

\section{Keywords:} \\ diffusion barrier; photocatalysis; reactive sputtering; $\mathrm{SiN}_{x}$; sol-gel; \\ titanium dioxide film; $\mathrm{TiO}_{2}$ \\ Beilstein J. Nanotechnol. 2015, 6, 2039-2045. \\ doi:10.3762/bjnano.6.207 \\ Received: 29 June 2015 \\ Accepted: 17 September 2015 \\ Published: 16 October 2015 \\ Associate Editor: N. Motta \\ (c) 2015 Ghazzal et al; licensee Beilstein-Institut. \\ License and terms: see end of document.
}

\begin{abstract}
We investigate the effect of the thickness of the silicon nitride $\left(\mathrm{SiN}_{x}\right)$ diffusion barrier on the structural and photocatalytic efficiency of $\mathrm{TiO}_{2}$ films obtained with different processes. We show that the structural and photocatalytic efficiency of $\mathrm{TiO}_{2}$ films produced using soft chemistry (sol-gel) and physical methods (reactive sputtering) are affected differentially by the intercalating $\mathrm{SiN}_{x}$ diffusion barrier. Increasing the thickness of the $\mathrm{SiN}_{x}$ diffusion barrier induced a gradual decrease of the crystallite size of $\mathrm{TiO}_{2}$ films obtained by the sol-gel process. However, $\mathrm{TiO}_{2}$ obtained using the reactive sputtering method showed no dependence on the thickness of the $\operatorname{SiN}_{x}$ barrier diffusion. The $\mathrm{SiN}_{x}$ barrier diffusion showed a beneficial effect on the photocatalytic efficiency of $\mathrm{TiO}_{2}$ films regardless of the synthesis method used. The proposed mechanism leading to the improvement in the photocatalytic efficiency of the $\mathrm{TiO}_{2}$ films obtained by each process was discussed.
\end{abstract}

\section{Introduction}

Titanium dioxide thin films in active phase (mostly anatase) have been widely studied due to their ability to produce strong oxidant species on the surface under UV light exposure [1] and to become super-hydrophilic [2]. One example of an application of this technology taking advantage of these combined properties is self-cleaning glass, which has transitioned from a promising technology to a global market product.

The contamination of titanium dioxide grown on soda lime glass (SLG) occurs during the calcination step and is due to the 
diffusion of alkali elements (especially sodium ions, $\mathrm{Na}^{+}$) [3,4]. Usually, $\mathrm{TiO}_{2}$ is amorphous when deposited at low temperature $[5,6]$. Heat treatment at a higher temperature (around $450{ }^{\circ} \mathrm{C}$ ) is usually required in order to obtain the photoactive anatase phase. However, $\mathrm{Na}^{+}$ions have a detrimental effect on the photocatalytic efficiency of $\mathrm{TiO}_{2}[3,4,7]$. The poisoning effect of the $\mathrm{Na}^{+}$ions on the photocatalytic activity occurs in different ways and depends on their concentration, for example: (a) $\mathrm{Na}^{+}$ ions increase the temperature of anatase formation and increase the particle size [4,7], (b) $\mathrm{Na}^{+}$ions inhibit the formation of the anatase phase and act as a recombination center of photo-generated electron-hole pairs [3], and (c) $\mathrm{Na}^{+}$ions induce the formation of brookite or sodium titanate $\left(\mathrm{Na}_{2} \mathrm{O}_{x} \mathrm{TiO}_{2}\right)$, which is less photoactive than the anatase form [8]. In order to prevent this poisoning effect, various strategies have been reported including ion exchange via the formation of a thin protonexchanged surface layer [3] or a post-treatment of the $\mathrm{TiO}_{2}$ films by hydrochloric acid [9], and the usage of a diffusion barrier intercalated between the substrate and the $\mathrm{TiO}_{2}$ film $[6,10]$. The most widely used diffusion barriers are $\mathrm{SiO}_{2}[10,11]$ and $\mathrm{SiN}_{x}$ [6] layers. $\mathrm{SiN}_{x}$ diffusion barriers show better efficiency than $\mathrm{SiO}_{2}$ with respect to inhibition of the diffusion of $\mathrm{Na}^{+}$ions [6]. The sodium ion concentration (which diffuses at the film surface) is strongly related to the thickness of the $\mathrm{SiN}_{x}$ layer [12]. Depending on the coating process, the thickness threshold required to prevent sodium ion diffusion and to guarantee a $\mathrm{Na}^{+}$-free $\mathrm{TiO}_{2}$ film is $100 \mathrm{~nm}$ [6] and $30 \mathrm{~nm}$ [12] for the reactive sputtered method and plasma-enhanced chemical vapor deposition, respectively.

In this paper, we studied the effect of the $\mathrm{SiN}_{x}$ thickness on thin $\mathrm{TiO}_{2}$ layers coated by either a soft chemistry (sol-gel) or physical (reactive sputtering) method. In earlier work, we studied the concentration of $\mathrm{Na}^{+}$ions as a function of the $\mathrm{SiN}_{x}$ diffusion barrier thickness using extremely sensitive surface analysis techniques (X-ray photoelectron spectroscopy (XPS) and sputtered neutral mass spectrometry (SNMS)) $[5,6,13]$. Aubry et al. showed that the concentration of $\mathrm{Na}^{+}$ions increases with a decrease of the $\mathrm{SiN}_{x}$ diffusion barrier of thickness less than $150 \mathrm{~nm}$ [13]. Even though no surface analysis was performed in this study, we assume the $\mathrm{Na}^{+}$ion concentration is reasonably correlated to the $\mathrm{SiN}_{x}$ thickness (below $150 \mathrm{~nm}$ ). In the present work, we report the unexpected effect of $\mathrm{SiN}_{x}$ thickness (correlated to $\mathrm{Na}^{+}$ion concentration) on the structural $\mathrm{TiO}_{2}$ films as a function of the preparation method. Finally, we discuss the effect of the $\mathrm{SiN}_{x}$ thickness on the photocatalytic efficiency of the $\mathrm{TiO}_{2}$ films with the degradation of Orange II dye.

\section{Experimental}

All of the reagents used in this work were of analytical grade and were used with no further purification and are as follows:
titanium(IV) isopropoxide (TTIP) (Aldrich, 97\%); ethanol absolute grade (99.9\%); hydrochloric acid (37\%) and Orange II (Sigma Chemical Co.).

\section{$\mathrm{SiN}_{x}$ diffusion barrier}

In order to prevent the diffusion of sodium ions from the SLG (which contains 14 wt $\%$ of $\mathrm{Na}_{2} \mathrm{O}$ ), a $\mathrm{SiN}_{x}$ layer was introduced between the $\mathrm{TiO}_{2}$ film and the SLG substrate. To determine the critical effect of the thickness of the $\mathrm{SiN}_{x}$ diffusion barrier, the thickness of the barrier layer was varied by adjusting the reactive sputtering time using a custom in situ interferometry method described in detail elsewhere [14].

\section{Sol-gel dip coating of $\mathrm{TiO}_{2} / \mathrm{SiN}_{x} / \mathrm{SLG}$}

The $\mathrm{TiO}_{2}$ films prepared using the sol-gel process is described in detail elsewhere [7]. Briefly, titanium(IV) isopropoxide is used as a precursor to synthesize the $\mathrm{TiO}_{2}$ sol via an acidcatalyzed sol-gel process at room temperature by dissolving $10 \mathrm{~mL}$ of titanium(IV) isopropoxide in $50 \mathrm{~mL}$ of absolute ethanol under magnetic stirring. The hydrolysis of the precursor is catalyzed by adding $1.3 \mathrm{~mL}$ of $\mathrm{HCl}$ (Sigma-Aldrich, ACS reagent, $37 \%)$. The sol is stirred for $30 \mathrm{~min}$ and then a mixture of water $(0.6 \mathrm{~mL})$ and absolute ethanol $(50 \mathrm{~mL})$ are added dropwise, followed by magnetic agitation for an additional $2 \mathrm{~h}$. The experiment was carried out under argon atmosphere.

The dip-coating process is used to grow the $\mathrm{TiO}_{2}$ films on SLG and on SLG coated with a $\mathrm{SiN}_{x}$ diffusion barrier. The substrates were dipped into and pulled out of the sol at a speed of $11.5 \mathrm{~cm} \cdot \mathrm{min}^{-1}$. The films were dried in air at $70{ }^{\circ} \mathrm{C}$ for $5 \mathrm{~min}$ between each layer and the coating procedure was repeated as many times as necessary to obtain a $40 \mathrm{~nm}$ thickness. The films were dried overnight at $80{ }^{\circ} \mathrm{C}$ and then calcinated in air at $450{ }^{\circ} \mathrm{C}$ for $2 \mathrm{~h}$ with a heating rate of $5{ }^{\circ} \mathrm{C} \cdot \mathrm{min}^{-1}$.

\section{Reactive sputtering of $\mathrm{TiO}_{2} / \mathrm{SiN}_{x} / \mathrm{SLG}$}

The details of the sputtering procedure are described elsewhere [6]. $\mathrm{TiO}_{2}$ films were deposited on SLG and $\mathrm{SiN}_{x} / \mathrm{SLG}$ systems by direct current sputtering from a metallic Ti target in an $\mathrm{Ar} / \mathrm{O}_{2}$ reactive gas mixture. The discharge current was regulated at $0.5 \mathrm{~A}$ and the resulting discharge voltage was $497 \mathrm{~V}$. The total pressure was adjusted at $3.36 \pm 0.07 \mathrm{~Pa}$, while the $\mathrm{Ar}$ and $\mathrm{O}_{2}$ flow rates were fixed at 30 and $4 \mathrm{sccm}$, respectively. Special attention was paid to the controlled deposition of $\mathrm{TiO}_{2}$ films with a thickness in the range of $250-400 \mathrm{~nm}$. The substrates were fixed on a rotating substrate holder that was parallel to the target surface. The $\mathrm{SiN}_{x} /$ glass substrates were placed in the same position on the substrate holder (separated from the axis of the target by $50 \mathrm{~mm}$ at a fixed angle of $75^{\circ}$ ) to ensure reproducibility. Using cold deposition, the $\mathrm{TiO}_{2}$ coatings were calcinated at $450{ }^{\circ} \mathrm{C}$ for $2 \mathrm{~h}$ with a heating rate of $50{ }^{\circ} \mathrm{C} \cdot \mathrm{min}^{-1}$. 


\section{Characterization}

The coating morphology was investigated by scanning electron microscopy (SEM) using a Philips XL30 SFEG equipped with a field effect gun. The structural properties of the films were determined by X-ray diffraction (XRD) using Co $\mathrm{K} \alpha$ radiation at grazing incidence $\left(0.05^{\circ}\right)$. Silicon powder was dispersed on the coating surface in order to calibrate the diffractograms.

The photocatalytic activity of the films was evaluated by observing the photobleaching of Orange II (OII) dye with an initial concentration $[\mathrm{OII}]=10 \mathrm{mg} \cdot \mathrm{L}^{-1}$ over the course of $2 \mathrm{~h}$ as a pollutant model. The details of the procedure and the photoreactor used were reported elsewhere in detail [7]. The photoreactor was placed in a solar box (Atlas, Suntest CPS + ) equipped with a Xe lamp as a light source $(300 \mathrm{~nm}<\lambda<800 \mathrm{~nm})$ to simulate natural UV-vis radiation. An incident power density of $23.3 \mathrm{~W} \cdot \mathrm{m}^{-2}$ was measured by a power meter at the sample location. Before each experiment, a blank reference with UV-vis light illumination of an SLG substrate without a $\mathrm{TiO}_{2}$ coating was performed. After $2 \mathrm{~h}$ of exposure, the observed decrease in the peak at $485.5 \mathrm{~nm}$ was less than $0.02 \%$ of the initial absorbance.

The bleaching of the dye was thus quantitatively evaluated by recording the "real time" evolution of the maximum absorbance value of the OII, at $485.5 \mathrm{~nm}$, at neutral $\mathrm{pH} 7.2$, using a quartz circulating cell placed in a UV-vis spectrometer. The photocatalytic activity of the films was quantitatively evaluated by comparing the bleaching reaction rates. The degradation rate can be described by a pseudo-one-order model when the dye concentration is low as, $\ln C_{0} / C=k_{\mathrm{a}} t$, where $C_{0}$ is the initial dye concentration $\left(\mathrm{mg} \cdot \mathrm{L}^{-1}\right)$.

\section{Results and Discussion $\mathrm{TiO}_{2}$ films morphology}

Figure 1 shows SEM images highlighting the $\mathrm{TiO}_{2}$ film morphology resulting from the sol-gel process and calcination at $450{ }^{\circ} \mathrm{C}$ for an increasing $\mathrm{SiN}_{x}$ barrier thickness. The surface of the film resulting from the sol-gel method was uniform. The average grain size was about $30-50 \mathrm{~nm}$ when a $\mathrm{TiO}_{2}$ film was directly grown on the SLG. The grain size appeared to be reduced and the thickness of the $\mathrm{SiN}_{x}$ barrier decreased. The evolution of the grain size of $\mathrm{TiO}_{2}$ nanoparticles is also confirmed by the results extracted from the XRD patterns (Figure 5a). The film thickness, estimated from the cross section, indicates that the films are about $40 \mathrm{~nm}$ thick (Figure 1b).

The surface morphology of the annealed $\mathrm{TiO}_{2}$ coatings synthesized on $\mathrm{SiN}_{x} / \mathrm{SLG}$ substrates by reactive sputtering is presented in Figure 2. The film surface does not show a major difference

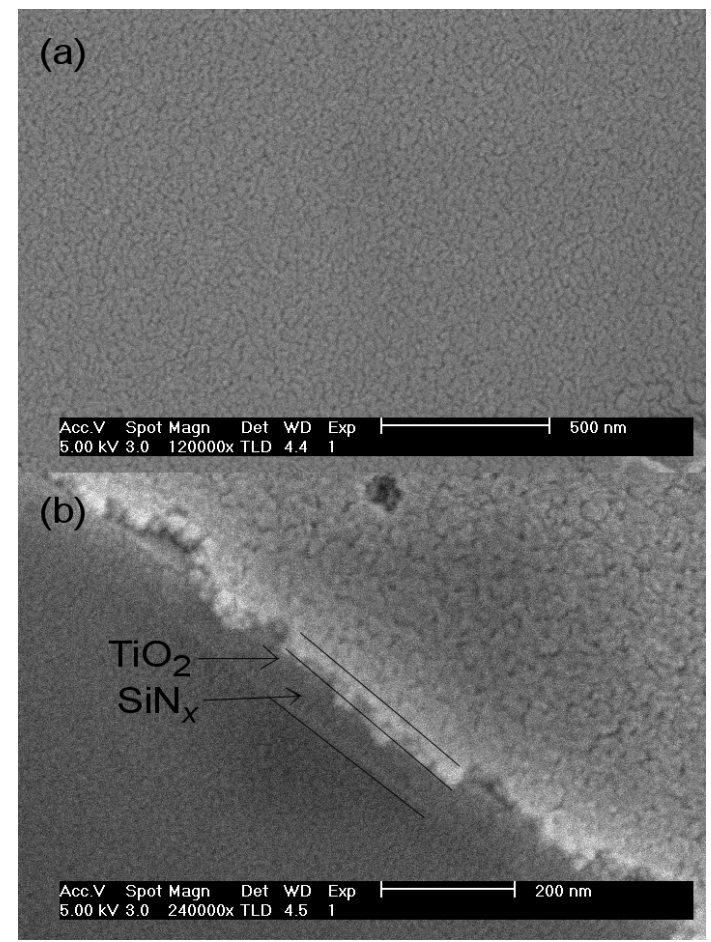

Figure 1: SEM images of the (a) top surface and (b) cross section of the sol-gel $\mathrm{TiO}_{2}$ films grown on $75 \mathrm{~nm}$ thick $\mathrm{SiN}_{\chi} / \mathrm{SLG}$ after annealing at $450^{\circ} \mathrm{C}$.

when the thickness of $\operatorname{SiN}_{x}$ barrier increases. The coatings treated at $450{ }^{\circ} \mathrm{C}$ show small cracks on the surface. The cracks are the same regardless of barrier thickness. This could be a consequence of the accumulation of intrinsic tensile stress induced by the crystallization of $\mathrm{TiO}_{2}$ [7]. As deposited on $\mathrm{SiN}_{x} / \mathrm{SLG}$ following the described procedure, the $\mathrm{TiO}_{2}$ films are amorphous and an annealing step at high temperature is needed to obtain the photoactive phase (anatase). The growth of $\mathrm{TiO}_{2}$ in its anatase form induces an internal tensile stress, which creates cracks in the films. The average grain size of $\mathrm{TiO}_{2}$ is estimated to be $20-40 \mathrm{~nm}$, according to the SEM images. The average grain size is not affected by the variation of the $\operatorname{SiN}_{x}$ barrier thickness. From the fragmented cross-sections (Figure 2b), the film morphology appeared to be composed of distinguishable columns separated by boundaries, which corresponds to an intracolumnar porosity. Operating at pressures higher than the dense-to-columnar transition pressure (used in our study) enable such a structure to be obtained. The resulting films exhibited a high specific surface area.

\section{$\mathrm{TiO}_{2}$ film structure}

The X-ray diffraction (XRD) patterns of the $\mathrm{TiO}_{2}$ films grown on $\mathrm{SiN}_{x} / \mathrm{SLG}$ using different methods and heat treated at $450{ }^{\circ} \mathrm{C}$ are presented in Figure 3 and Figure 4. It is worth noting that the films, as deposited on SLG or on $\mathrm{SiN}_{x} / \mathrm{SLG}$ systems, are 


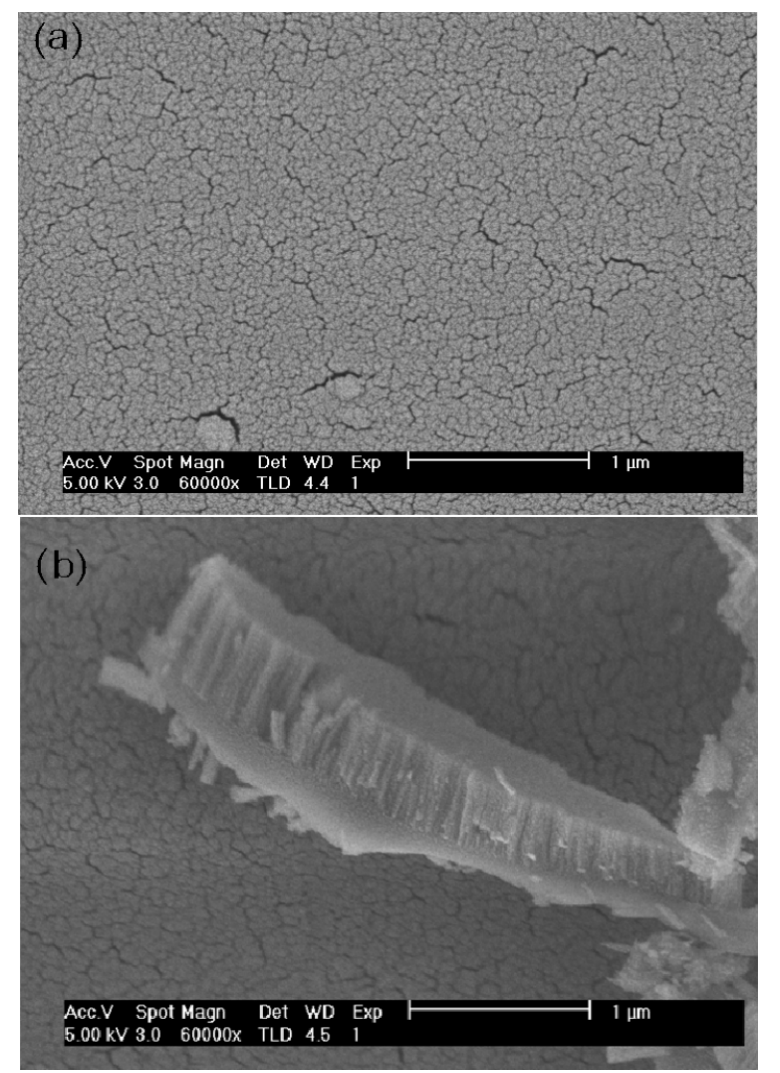

Figure 2: SEM images of (a) the top surface and (b) the cross-section of the magnetron sputtered $\mathrm{TiO}_{2}$ films grown on $\mathrm{SiN}_{x} / \mathrm{SLG}$ after annealing at $4500^{\circ} \mathrm{C}$.

amorphous regardless of the deposition method. After the calcination step, $\mathrm{TiO}_{2}$ grown on SLG is crystallized in the anatase structure regardless of the method and the $\mathrm{SiN}_{x}$ diffusion barrier does not affect the crystallization of the films. This result suggested that the SLG substrate does not affect the crystallization step of the amorphous $\mathrm{TiO}_{2}$ films, which is in contrast with previous reports. Novota et al. found that $\mathrm{TiO}_{2}$ films deposited on SLG exhibited a brookite dominant crystalline phase [10]. Koo et al. reported that a $\mathrm{SiN}_{x}$ diffusion barrier is necessary to crystallize $\mathrm{VO}_{2}$ films [12]. The XRD patterns reveal a preferential [101] orientation for the sol-gel $\mathrm{TiO}_{2}$ films, whereas the reactive sputtered $\mathrm{TiO}_{2}$ films show a [001] preferential orientation. In order to understand the effect of the diffusion barrier thickness on the structure of the $\mathrm{TiO}_{2}$ films, the full width at half maximum (FWHM) of the preferential reflection is presented in Figure $3 \mathrm{~b}$ and Figure $4 \mathrm{~b}$.

Two distinct behaviors are observed depending on the coating method. While the FWHM of the [101] diffraction patterns of the $\mathrm{TiO}_{2}$ made by the sol-gel method decreased with decreasing diffusion barrier thickness as compared to that measured for the [101] and [004] diffraction plans in the case of $\mathrm{TiO}_{2}$ films made (a)
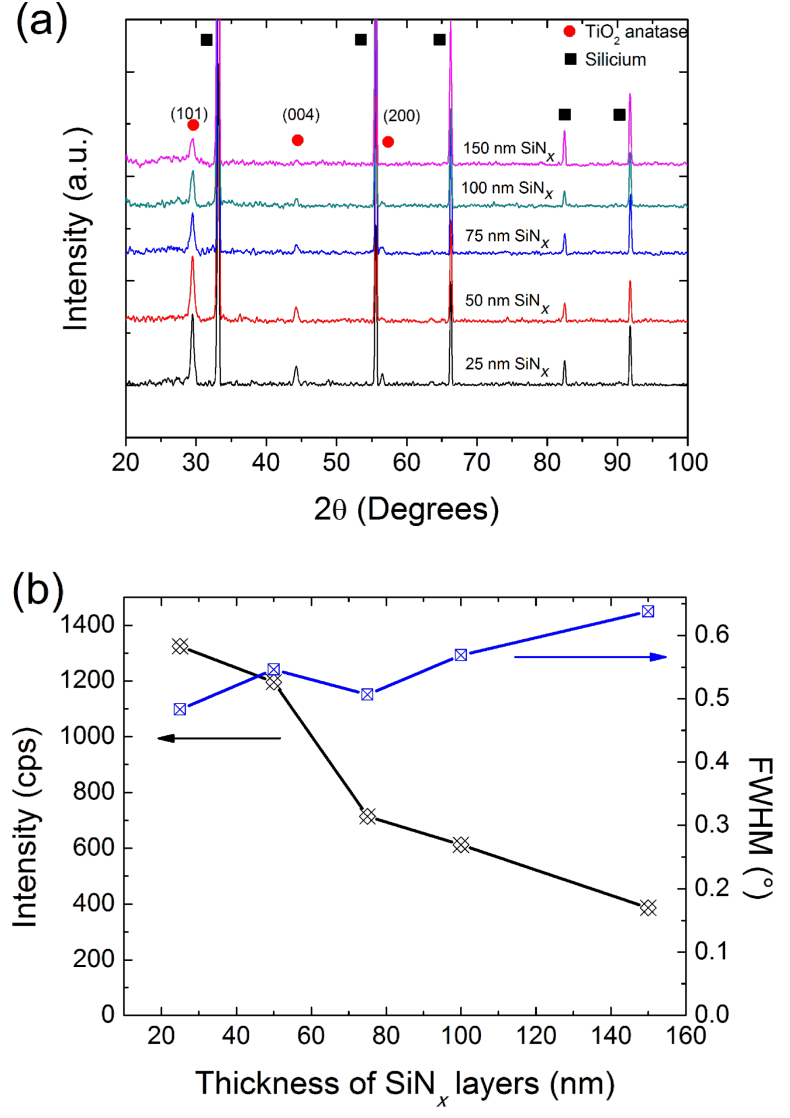

Figure 3: (a) XRD patterns and (b) FWHM and the intensity of the (101) plane of the sol-gel $\mathrm{TiO}_{2}$ coatings as a function of the $\mathrm{SiN}_{x}$ layer thickness.

by reactive sputtering, which do not show a significant change. The intensity of the peak diffraction decreased for the sol-gel coating, whereas it remained unchanged for the film made by the reactive sputtering method. According to Scherrer's equation [15], the crystallite size was estimated for the $\mathrm{TiO}_{2}$ sol-gel (SG-TiO $)$ coating and the magnetron sputtered $\mathrm{TiO}_{2}$ (MS$\mathrm{TiO}_{2}$ ) grown on the glass and on $\mathrm{SiN}_{x} /$ glass was compared by measuring the FWHM of the (101) diffraction peaks. It was found that for $\mathrm{MS}-\mathrm{TiO}_{2}$ samples, the presence of the diffusion barrier does not affect the crystallites size, which was about 24-30 $\mathrm{nm}$ in both cases. This result is in agreement with our previous study but for a much thicker $\mathrm{SiN}_{x}$ diffusion barrier [6]. This suggests that the crystallite size of the $\mathrm{TiO}_{2}$ films obtained by magnetron sputtering does not depend on the thickness of the $\mathrm{SiN}_{x}$. Furthermore, no difference has been observed between the crystallite size of the MS- $\mathrm{TiO}_{2}$ films grown on SLG or on $\mathrm{SiN}_{x} / \mathrm{SLG}$, which suggested that the $\mathrm{SiN}_{x}$ layer does not affect the crystallite growth of the $\mathrm{TiO}_{2}$ during the heat treatment. However, the crystallite size of $\mathrm{SG}_{-} \mathrm{TiO}_{2}$ films decreases gradually as the thickness of the $\mathrm{SiN}_{x}$ diffusion barrier increases. $\mathrm{TiO}_{2}$ thin films grown on SLG were obtained and discussed in 

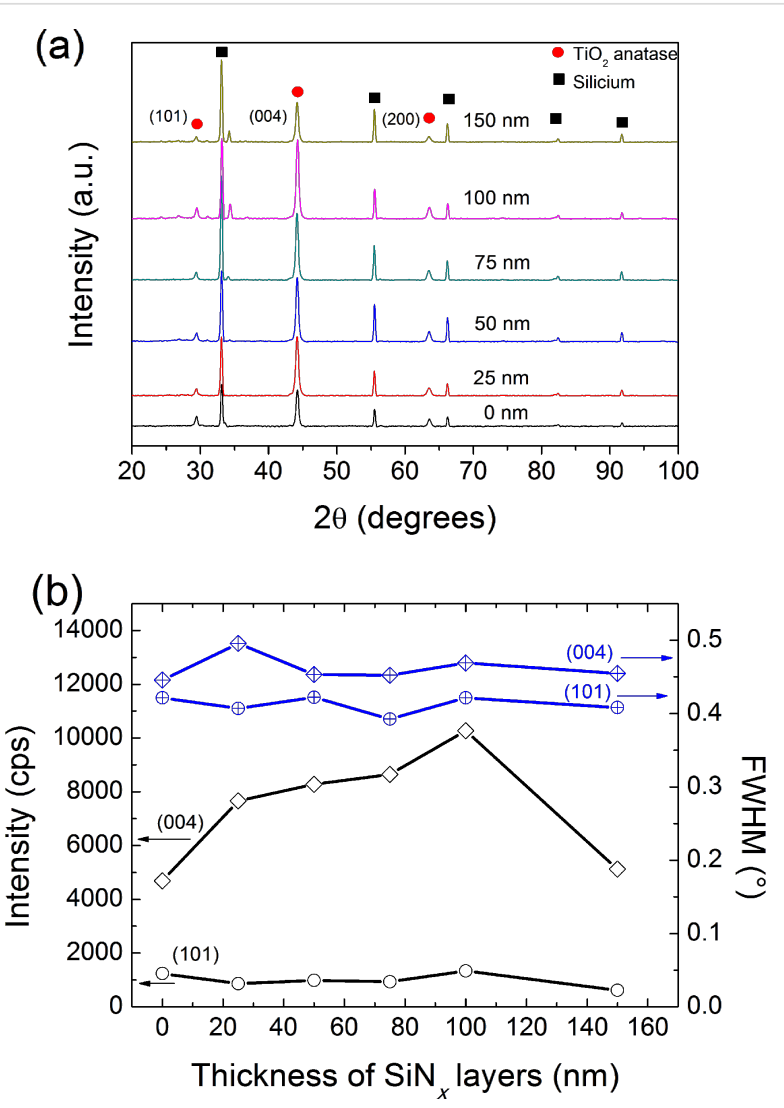

Figure 4: (a) XRD patterns and (b) FWHM of the (101) and (004) planes and their intensity of the $\mathrm{TiO}_{2}$ coatings as a function of the thickness of the $\mathrm{SiN}_{X} / \mathrm{SLG}$ films.

our previous study [7]. The $\mathrm{TiO}_{2} / \mathrm{SLG}$ sample presented a granular structure with a grain size of $\approx 30-50 \mathrm{~nm}$. The crystallite started with a size around $30-50 \mathrm{~nm}$ when $\mathrm{SG}-\mathrm{TiO}_{2}$ was grown on SLG, which decreased to approximately $18 \mathrm{~nm}$. Similar results were observed for $\mathrm{TiO}_{2}$ film obtained by sol-gel methods on various substrates. Nam et al. reported that the $\mathrm{Na}^{+}$ ions in the $\mathrm{TiO}_{2}$ films induce an increase in their crystallite size [4]. The diffusion of the ions at the grain boundary during the heat treatment is in competition with the nucleation/growth of the anatase crystallite, which induces an increase in the temperature required for nucleation, while the activation energy of the grain growth decreases [16]. The efficiency of the $\mathrm{SiN}_{x}$ diffusion barrier to inhibit sodium diffusion from the SLG must be related to its thickness. It is well known that the SLG contains $14 \mathrm{wt} \%$ of $\mathrm{Na}_{2} \mathrm{O}$, and the calcination at high temperature of the $\mathrm{TiO}_{2}$ films induces the diffusion of $8 \%$ of the $\mathrm{Na}^{+}$ ions from the substrate to the $\mathrm{TiO}_{2}$ surface [17]. Aubry and coworkers [6] reported that the $\mathrm{SiN}_{x}$ diffusion barrier with a $100 \mathrm{~nm}$ thickness is sufficient to hinder the alkali diffusion (only $2 \%$ of sodium ions were detected by SNMS in the $\mathrm{TiO}_{2}$ film surface), and increasing the thickness up to $1,000 \mathrm{~nm}$ does not further reduce the concentration of $\mathrm{Na}^{+}$ions. Koo et al. [12] showed that the $\mathrm{SiN}_{x}$ diffusion barrier contributes to the formation of the $\mathrm{VO}_{2}$ crystalline phase. From XPS results, it was concluded that the amount of sodium ions diffused to the top $\mathrm{VO}_{2}$ layer decreases gradually as the thickness decreases from $100 \mathrm{~nm}$ to $10 \mathrm{~nm}$. Increasing the $\mathrm{SiN}_{x}$ diffusion barrier thickness indirectly induces the decrease in the crystallite size of the SG-TiO 2 film. A similar behavior has been observed for $\mathrm{TiO}_{2}$ films grown on various types of glasses containing different concentrations of sodium in their composition $[4,7]$.

\section{Photocatalytic efficiency of SG- $\mathrm{TiO}_{2}$ and $\mathrm{MS}-\mathrm{TiO}_{2}$ films as a function of $\mathrm{SiN}_{x}$ diffusion barrier thickness}

The photocatalytic activity of the films was evaluated by following the photobleaching reaction rate of OII dye as a function of the irradiation time (Figure 5). According to our results, the reaction rate follows a Langmuir-Hinshelwood kinetic, which can be described by a pseudo-first-order model since the dye concentration is low. No significant change was observed for the initial absorbance (concentration) of OII in the presence of an uncoated SLG under UV-vis illumination or in the dark in the presence of the $\mathrm{TiO}_{2}$ photocatalyst. Thus, the OII was not
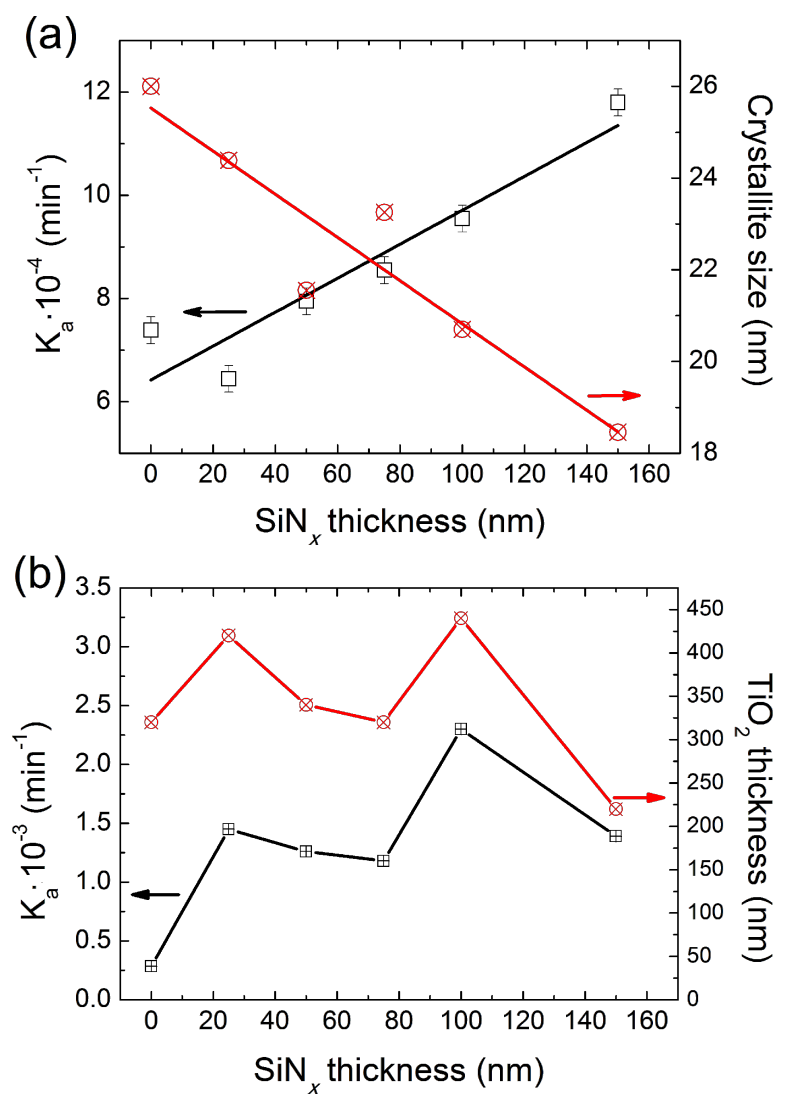

Figure 5: Evolution of the kinetics of the degradation rate of OII. The crystallite size and $\mathrm{TiO}_{2}$ thickness of (a) a SG-TiO film and (b) the magnetron sputtered $\mathrm{TiO}_{2}$ film as a function of $\mathrm{SiN}_{x}$ thickness. 
photobleached by photolysis nor was it adsorbed at the surface of the photocatalyst, which suggests a neglected effect of the specific surface area of the film on the photocatalytic efficiency. The photobleaching of the OII dye in the presence of the catalyst was performed at neutral $\mathrm{pH} 7.2$ during $2 \mathrm{~h}$ of UV-vis illumination. At neutral $\mathrm{pH}$, the bleaching of OII was caused by photo-oxidation via formation of radicals and/or a UV-induced modification of the surface, leading to the adsorption/bleaching of the azo molecule [18]. This means that even the dye molecule OII could absorb visible light to produce the excited singlet and/or triplet state of the OII molecule [19], the OII may be able to sensitize the $\mathrm{TiO}_{2}$ photocatalyst. However, the degradation of the OII dye via the sensitization mechanism has only a minor contribution to the overall degradation rate [7].

The results are depicted as the apparent constant rate of the OII degradation as a function of the illumination time. A different behavior for $\mathrm{SG}-\mathrm{TiO}_{2}$ and $\mathrm{MS}-\mathrm{TiO}_{2}$ films was observed. For the films made by the sol-gel method, the degradation rate of the OII dye increases with increasing thickness of the $\mathrm{SiN}_{x}$ diffusion barrier. This suggests that the kinetic of the degradation of the OII dye is inversely proportional to the crystallite size of $\mathrm{TiO}_{2}$. Reducing the crystallite size of the $\mathrm{SG}-\mathrm{TiO}_{2}$ (from $30-50$ to $18 \mathrm{~nm}$ ) by increasing the $\mathrm{SiN}_{x}$ diffusion barrier thickness affects the interfacial electron transfer rate [20]. The photogenerated electron-hole pair produced in the bulk of the photocatalyst during the illumination diffuses faster to reach the surface, since the distance traveled is reduced by the smaller crystallite, and redox reactions with species present on the surface takes place. This leads to the rapid formation of radical species $\left(\mathrm{O}_{2}{ }^{--}, \mathrm{HO}_{2}{ }^{\bullet}, \mathrm{HO}^{\bullet}\right)$, followed by a rapid degradation of the OII dye. For the MS-TiO ${ }_{2}$ system, once the $\mathrm{SiN}_{x}$ diffusion barrier has been intercalated between the $\mathrm{TiO}_{2}$ film and the SLG substrate, the degradation kinetic rate of OII shows a sudden improvement. The degradation rate of OII becomes five times greater than that of the $\mathrm{TiO}_{2}$ film grown solely on SLG with a $\mathrm{SiN}_{x}$ layer of about $25 \mathrm{~nm}$, and then the degradation rate of the OII dye becomes independent of the diffusion barrier thickness. In this case, the crystallite size of the $\mathrm{TiO}_{2}$ photocatalyst is not responsible for the change in photocatalytic efficiency. This result suggests that $\mathrm{SiN}_{x}$ inhibits the diffusion of $\mathrm{Na}^{+}$ions into the films during the calcination step, which is actually a well-documented fact $[4,7,21]$. Tada and Tanaka [21] attributed the clear difference observed in the photocatalytic activity between sol-gel $\mathrm{TiO}_{2}$ films grown on quartz and SLG to the presence of $\mathrm{Na}^{+}$ions acting as recombination centers for the photocarriers. Moreover, Koo et al. [12] show a clear correlation between the $\mathrm{SiN}_{x}$ diffusion barrier thickness and the $\mathrm{Na}^{+}$ ion concentration on the surface of the films during the calcination step. This suggests that a $25 \mathrm{~nm} \mathrm{SiN}_{x}$ diffusion barrier is sufficient to inhibit sodium diffusion. Consequently, more elec- tron-hole pairs are photo-generated at the $\mathrm{TiO}_{2}$ surface, leading to an increase in the radical species responsible for the degradation of OII. For an equivalent $\mathrm{TiO}_{2}$ thickness, the degradation rate of OII is relatively similar.

\section{Conclusion}

We investigated the structural and photocatalytic properties of titanium dioxide films obtained by low temperature sol-gel and reactive sputtering processes for $\mathrm{SiN}_{x}$ diffusion barriers of different thicknesses. The structural properties of the $\mathrm{TiO}_{2}$ films was affected by the process used for the production of the films. The preferential orientation of the anatase phase obtained for the samples produced from the sol-gel process is the (001) plane, whereas those from the reactive magnetron sputtering process show a preferential (004) orientation plane. Regardless of the process used to synthesize the $\mathrm{TiO}_{2}$ films, the intercalating $\mathrm{SiN}_{x}$ diffusion barrier between the photocatalyst and the soda lime glass showed a beneficial effect on the photocatalytic efficiency. An increased $\mathrm{SiN}_{x}$ diffusion barrier thickness resulted in a decrease in the crystallite size of the $\mathrm{TiO}_{2}$ film when produced by the sol-gel method, and consequently, the photocatalytic degradation of the OII dye was improved. However, when the reactive sputtering method was used, the thickness of the diffusion barrier had no effect on the structural properties of the $\mathrm{TiO}_{2}$ films.

\section{References}

1. Fujishima, A.; Honda, A. Nature 1972, 238, 37. doi:10.1038/238037a0

2. Wang, R.; Hashimoto, K.; Fujishima, A.; Chikuni, M.; Kojima, E.; Kitamura, A.; Shimohigoshi, M.; Watanabe, T. Nature 1997, 388, 431. doi:10.1038/41233

3. Paz, Y.; Heller, A. J. Mater. Res. 1997, 12, 2759. doi:10.1557/JMR.1997.0367

4. Nam, H.-J.; Amemiya, T.; Murabayashi, M.; Itoh, K. J. Phys. Chem. B 2004, 108, 8254. doi:10.1021/jp037170t

5. Aubry, E.; Miska, P.; Gigleux, L.; Mézin, A.; Demange, V.; Billard, A. Surf. Coat. Technol. 2008, 202, 4980. doi:10.1016/j.surfcoat.2008.04.097

6. Aubry, E.; Ghazzal, M. N.; Demange, V.; Chaoui, N.; Robert, D.; Billard, A. Surf. Coat. Technol. 2007, 201, 7706. doi:10.1016/j.surfcoat.2007.03.003

7. Ghazzal, N. M.; Chaoui, N.; Aubry, E.; Koch, A.; Robert, D. J. Photochem. Photobiol., A 2010, 215, 11. doi:10.1016/j.jphotochem.2010.07.014

8. Kuznetsova, I. N.; Blaskov, V.; Stambolova, I.; Znaidi, L.; Kanaev, A. Mater. Lett. 2005, 59, 3820. doi:10.1016/j.matlet.2005.07.019

9. Yu, J.; Zhao, X. Mater. Res. Bull. 2001, 36, 97-107. doi:10.1016/S0025-5408(00)00475-X

10. Novotna, P.; Krysa, J.; Maixner, J.; Kluson, P.; Novak, P. Surf. Coat. Technol. 2010, 204, 2570-2575. doi:10.1016/j.surfcoat.2010.01.043

11. Lee, K.-S.; Lee, S. H. Mater. Lett. 2007, 61, 3516. doi:10.1016/j.matlet.2006.11.109

12. Koo, H.; You, H. W.; Ko, K.-E.; Kwon, O.-J.; Chang, S.-H.; Park, C Appl. Surf. Sci. 2013, 277, 237. doi:10.1016/j.apsusc.2013.04.031 
13. Aubry, E.; Lambert, J.; Demange, V.; Billard, A. Surf. Coat. Technol. 2012, 206, 4999. doi:10.1016/j.surfcoat.2012.06.012

14. Lapostolle, F.; Perry, F.; Billard, A. Surf. Coat. Technol. 2006, 201, 2633-2638. doi:10.1016/j.surfcoat.2006.05.015

15. Cullity, B. D. Elements of $X$-ray Diffraction; Addison-Wesley: Reading, MA, U.S.A., 1978.

16. Hukari, K.; Dannenberg, R.; Stach, E. A. J. Mater. Res. 2002, 17, 550. doi:10.1557/JMR.2002.0077

17. Ghazzal, M. N.; Chaoui, N.; Genet, M.; Gaigneaux, E. M.; Robert, D. Thin Solid Films 2011, 520, 1147. doi:10.1016/j.tsf.2011.08.097

18. Ollis, D. F. J. Phys. Chem. B 2005, 109, 2439-2444.

doi:10.1021/jp040236f

19. Stylidi, M.; Kondarides, D. I.; Verykios, X. E. Appl. Catal., B 2004, 47, 189. doi:10.1016/j.apcatb.2003.09.014

20. Carp, O.; Huisman, C. L.; Reller, A. Prog. Solid State Chem. 2004, 32, 33. doi:10.1016/j.progsolidstchem.2004.08.001

21. Tada, H.; Tanaka, M. Langmuir 1997, 13, 360. doi:10.1021/la960437d

\section{License and Terms}

This is an Open Access article under the terms of the Creative Commons Attribution License

(http://creativecommons.org/licenses/by/2.0), which permits unrestricted use, distribution, and reproduction in any medium, provided the original work is properly cited.

The license is subject to the Beilstein Journal of

Nanotechnology terms and conditions:

(http://www.beilstein-journals.org/bjnano)

The definitive version of this article is the electronic one which can be found at: doi:10.3762/bjnano.6.207 